\title{
FENTANYL AND TOOTH PULP EVOKED RESPONSES IN THE SPINAL TRIGEMINAL NUCLEUS CAUDALIS REGION
}

\author{
Yoshiaki NISHIJIMA and Yutaka SAKAI* \\ Medical Laboratory for Pharnacology, Central Rescarch Laboratories, \\ Sankyo Co., Lta., Shinagawa-ka, Tokyo 140, Japan
}

Accpled January 22, 1976

\begin{abstract}
Electrical activitis cvoked by tooth pulp stimulation were recorded in the subnucleus caudalis region of the spinal trigeminal nucleus, and the action of fentanyl, a short-acting narcotic, on these activitics was investigated in the $\alpha$-chloralose anesthetized cat. Fentanyl (20 or $40 \mu \mathrm{g}$. $\mathrm{g}$ i.v.) depressed the firs peak and potentiated the second one of negative potentials croked by pulp stimulation in the border area between the nucleus proprius ( $P r$ ) and the lateral reticular formation (LRF). Neurons, whose responses to pulp stimulation were depressed by fentanyl, were also predominantly localized in this region. Pulp-induced monophasic negative potential and spike discharges in the more ventro-medial portion of the LRf wore not affected by fentanyl. The effect of fentanyl on cells in the marginal zone varied from unit to unit. The selective action of fentanyl on neurons in the border area between the $\operatorname{Pr}$ and the LRF may partially explain the analgesic action of fentanyl.
\end{abstract}

Since Sjöqvist's surgery on the cervical tractotomy (1), it is considered that the subnucleus caudalis of the spinal trigeminal nucleus is concerned with a relay station of nociceptive and thermal sensation of the facial area (2). Cytoarchitccturally speaking, the subnucleus caudalis in humans has different features than the other two subnuclei of the spinal trigeminal nucleus (3). Similar differences are also observed in monkeys (3), cats (4) and rats (5). This morphological analogy between hunan and animals suggests that the neurons in the subnucleus caudalis in these aninals would also play a significant role in facial pain. Physiological data obtained with these animals partly support this hypothesis (6-10).

The subnucleus caudalis is assumed to be the site of action of narcotics, since lesion of the subnucleus caudalis markedly depressed the ffect of morphine or fentanyl on the jaw opening reflex induced by noxious stimuli (11-13). However, studics of drug actions on the evoked potentials in the subnucleus caudalis from tooth pulp, which consists exclusively of the small myelinated ( $A_{--i}$ ) fibers (14), were inconsistent: morphine (2-6 ngg $/ \mathrm{kg} \mathrm{i.v.)}$ depressed the evoked potential size in the dog (15), while no influence of the drug (up to $6 \mathrm{mg} / \mathrm{kg}$ i.v.) was evident in the rabbit (16). The subnucleus caudalis is subdivided into three anatomically difierent layers (the marginal zone, the substantia gelatinosa and the nucleus proprius (Pr)) (3), and the lateral reticular formation (LRF), which borders the ventromedial aspects, is also known to be closely related with input from the trigeminal nerve $(6,7,9)$. Therefore, it is possible that the nature of the croked potentials in the subnucleus caudalis may be classified into different subdivisions with each subdivision having different drus sensitivities. Thus, the inconsisicney observed in the morphine effect $(15,16)$ inay be

\footnotetext{
* Present address: Department of Pharmacologe. The National Defense Vedical College,

Tokorozawa, Saitama 350 , Japan
} 
due to differences in recording sites other than species differences.

In the present study, we attempted to elucidate the action of a narcotic in the subnucleus caudalis region; at first, the field potentials were utilized in order to determine their relations with the three subdivisions of the subnucleus caudalis and the LRF, and secondly, single neuron activities in these different layers induced by volleys in tooth pulp nerves were studied. Fentanyl citrate was the narcotic used (17). As this compound has a short-lasting action, multiple injections in a single experiment could be given.

\section{MATERIALS AND METHODS}

Experiments were carried out on 49 adult cats. Ether anesthesia was used only briefly during cannulations of the trachea, femoral artery and femoral vein, after which the animal was mounted on a stereotaxic apparatus. After discontinuing the ether inhalation, the animal was anesthetized with $\alpha$-chloralose ( $50 \mathrm{mg} / \mathrm{kg} \mathrm{i.v.)}$, immobilized with gallamine triethiodide (Teisan) and artificially respired. Rectal temperature was maintained at $37-38^{\circ} \mathrm{C}$ and systemic blood pressure was monitored during the course of the observations. The cervical spinal cord and lower medulla were exposed by suboccipital craniotomy and cervical laminectomy at $\mathrm{C}_{1}$ level. Exposed tissues were covered with a pool of warmed liquid paraffin.

Two small openings, approximately $1 \mathrm{~mm}$ apart, were drilled into the dentine of the upper and/or lower canine teeth on both sides, and bipolar stainless steel electrodes $(0.13$ $\mathrm{mm}$, diameter) were inserted into the holes. Amalgam was put into the openings and covered with dental cement together with electrodes. A single or paired monophasic square pulses of $0.5 \mathrm{msec}$ duration ( $5 \mathrm{msec}$ interval) were applied to the dentine electrodes via an isolation unit (MSE-40 and MSE-JH, Nihon Kohden) at a frequency of $0.3-1 \mathrm{~Hz}$. In the single neuron analysis, the modality of effective stimuli and the peripheral receptive field were roughly determined by touch, pressure or pin prick to the skin.

Glass microelectrodes, filled with $1 \mathrm{M} \mathrm{K}$-acetate or $3 \mathrm{M} \mathrm{NaCl}$ solution saturated with methylblue, with a resistance of $1-5 \mathrm{M} \Omega$, were used for recording the field potentials or single unit activities. These activities were displayed on a cathode-ray oscilloscope (RM 565, Tektronix) through a cathode follower and a DC amplifier, and were photographed. The field potentials were introduced to a computer of average transients (CAT 400B, Mnemotron), and 30 to 50 responses were superimposed and displayed on the oscilloscope for photographing. In order to avoid a possible mixing of records from axons, the data from monophasic positive spikes were discarded.

In order to prevent the possibility of the current spreading to extrapulpal receptors, the tooth pulp of the canine teeth was completely removed in 5 animals; that is, the incisal 2 to $3 \mathrm{~mm}$ of the canine crown was cut off and the incisal end of the pulp chamber was opened with a dental bar, so as to insert a hypodermic needle $(27 \mathrm{G})$. The pulp was then crushed by twisting an inserted hypodermic needle. The resistance $(50-300 \mathrm{k} \Omega)$ between the implanted electrodes was hardly changed after this procedure.

The location of the microclectrode tip in the upper spinal cord was marked by electrophoretic injection of methylblue (4-6, $/ \mathrm{A}, 10-15 \mathrm{~min})$ and was histologically identified in 
Nissl stained serial sections of the cord.

Fentanyl citrate (Janssen) was dissolved in $0.9 \%$ saline $(40, \mu \mathrm{g} / \mathrm{ml})$ and intravenously administered by slow injection.

\section{RESULTS}

Results will be separated into two main sections: firstly, distribution of evoked potentials in the subnucleus caudalis region and related neuron activities will be described, and secondly, fentanyl effects both on evoked potentials and neuron discharges will be discussed.

\section{Field potentials and associated single unit activities evoked by tooth pulp stimulation}

Field potential. Field potentials generated by ipsilateral upper canine tooth pulp stimulation were systematically recorded in the subnucleus caudalis region, 3 to $5 \mathrm{~mm}$ caudal to the obex in 3 cats. Figure 1 illustrates distributions of the potentials at a vertical level approximately $4 \mathrm{~mm}$ caudal to the obex. Traces of electrode penetrations into the depth are illustrated in the left. As seen in the right figure, only the negative field potential was observed in this region. Higher amplitudes up to several hundred $\not V$ were seen in the border area between the $\operatorname{Pr}$ and the LRF. The potential had an onset latency of 4.5-6.5 msec and an early peak at $8-12 \mathrm{msec}$, and its second peak appeared at $18-22 \mathrm{msec}$ and persisted for up to $50 \mathrm{mscc}$. These two peaks had different sensitivitics to a barbiturate (Fig. 2-B) or to fentanyl (Fig. 4-B). The second peak more of ten than the first one failed to respond to repetitive stimulation of the pulp (Fig. 2-A). Therefore, these two peaks appeared to be generated by two different mechanisms. Figure 2-A and -B illustrates such differential

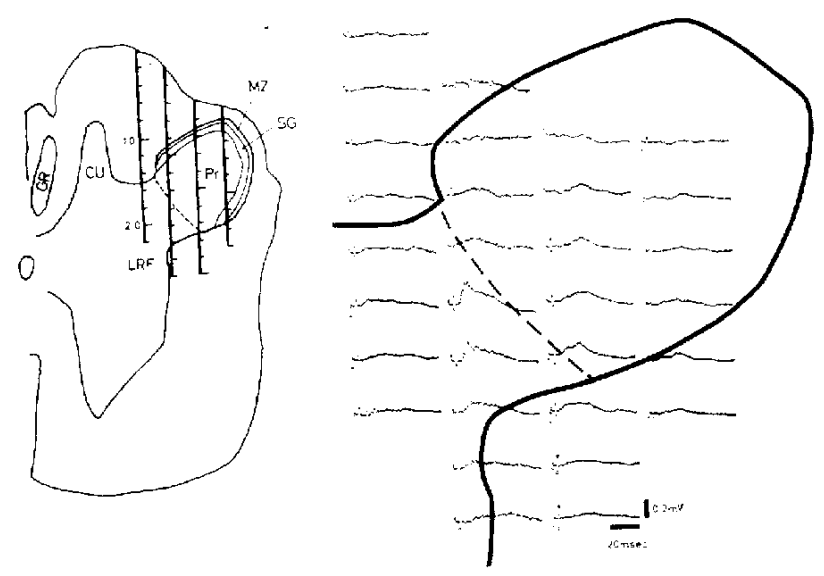

FIG. 1. Field potentials in the subnucleus caudalis region generated by tooth pulp stimulation. The figure on the left is a cross section at the upper cervical cord, 4 $\mathrm{mm}$ caudal to the obex. Each potential (average of 30 responses) in the right figure was recorded at each cross line on the elcctrode tracks in the left figure. Numbers at the tracks indicate the depth in mm from the dorsal surface. Abbreviations in this and succeding figures are as follows. $\mathrm{CU}$ : nucleus cuncatus; GR: nucleus gracilis; LRF : lateral reticular formation; MZ: marginal zone (subnucleus zonalis); Pr: nucleus proprius (subnucleus magnocellularis); SG: substantia gelatinosa (subnucleus gelatinosus). 
activities. By pulp stimulation at $5 \mathrm{~Hz}$, the second peak was abolished but the first persisted. Pentoburbital in dose of 5 mg'kg depressed markedly the later peak with little effect on the former. The potentials were completely abolished by the destruction of pulp (Fig. 2-C). No distinct field potential was induced in the marginal zone and the substantia gelatinosa of the subnucieus caudalis after pulp stimulation. Pctential studies in two other animals showed essentially the same distributions.

Single unit activity. In total, 89 neurons of 33 cats were responsive to the ipsilateral upper andor louter canine tooth pulp stimulation in the spinal trigeninal ara, $1-7 \mathrm{~mm}$ caudal to the

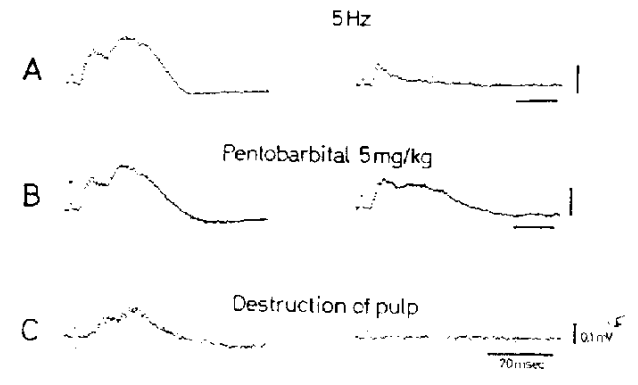

[JG. 2. Two components of negative field potentials evoked by pulp stimulation in the border area between the $\operatorname{Pr}$ and the I.RF. $\triangle$ and $B$ are averages of 50 responses, and $\mathrm{C}$ is an average of 30 . Pulp stimulation was given at $0.5 \mathrm{~Hz}$ except in the right figure in A. Potentials in the left column indicate the controls before cach treatmont. Right figures in A, B and $C$ show potentials at $5 \mathrm{H} /$, after pentobarbital injection (5 $\mathrm{mg} / \mathrm{kg}) \quad(0.5$ $\mathrm{Hz}$ ) and after destruction of pulp $(0.5 \mathrm{~Hz})$, respectively.

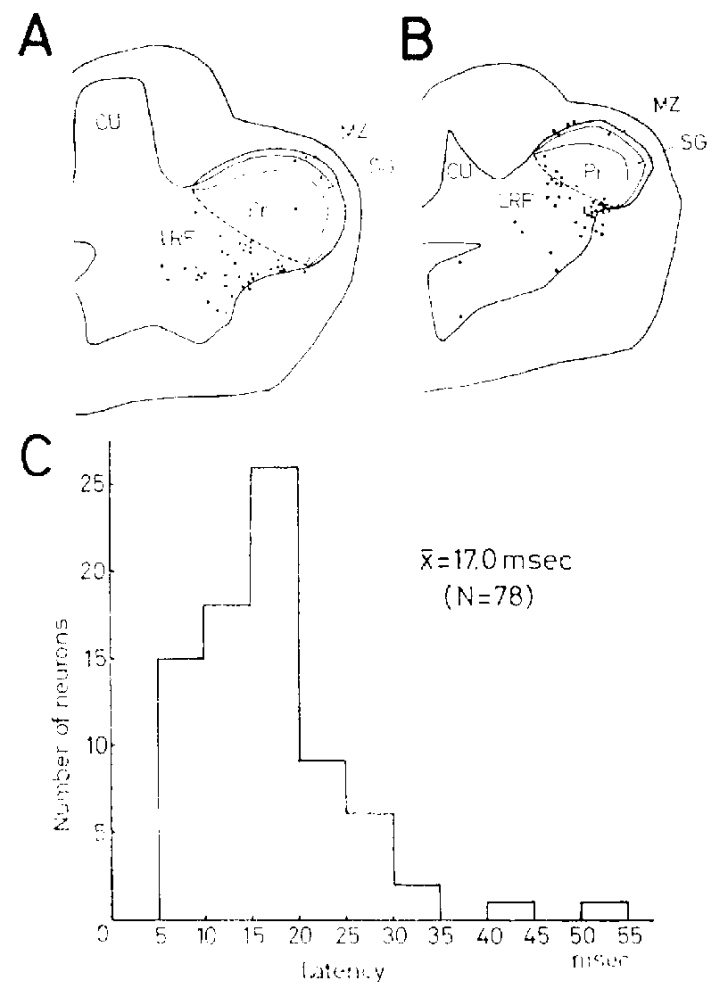

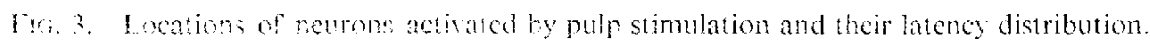

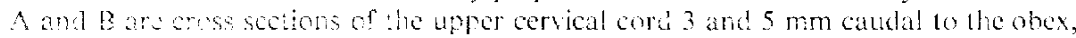
It purvely C indicates the latency distribution of cells in the Pr and the IRF. 
obex. These neurons responded to the supramaximal pulp stimulation with single or multiple spike discharges. Recording sites of 88 neurons were identified by methylblue staining techniques. They were projected on planes at the cord 3 and 5 mm caudal to the obex and are illustrated in Fig. 3-A and -B. Most of these (78 cells) were located in the LRF and in the border area between the $\mathrm{Pr}$ and the LRF; they were particularly concentrated in the area where the field potentials from the pulp were recorded. Response latencies of these cells ranged between 5.5 and $54.4 \mathrm{msec}$ (Fjg. 3r C), showing a modal peak at 15-20 msec. This peak latency was in approximately good parallel to the second peak (18-22 msec) of the pulp evoked potential. The shortest latency of cell discharges $(5.5 \mathrm{msec}$ ) was also in parallel with the onset latency of the field potential ( $4.5-6.5 \mathrm{msec})$. Eight cells responding with latencies of less than $10 \mathrm{msec}$ and with fewer spike discharges of less than 3 spikes per response were found mainly in the ventro-medial portion of the LRF. Seven cells responding with shorter latencies in the border area discharged with multiple spikes (5 to 13.4 spikes per response). Eight pulp-sensitive neurons were found in the marginal zonc or the substantia gelatinosa where no visible pulp induced-field potential had been recorded. Latencies of these neurons ranged between 10.0 and $82 \mathrm{msec}($ mean $=28.9 \mathrm{msec})$.

The modality of effective stimuli and the peripheral receptive field were successfully determined in 57 cells, including 4 in the marginal zone. Fifty-three cells were activated by touch or pressure of various areas on the face. Only 4 cells, including 3 in the marginal zone, were not excited by such stimulation, but were excited by a pin prick. The receptive areas of cells in the LRF were large, usually covering territories of two or three main branches of the trigeminal nerve, and 5 of these neurons were activated even by touch or tap of the body trunk and/or forelimbs. Neurons in the subnucleus caudalis usually revealed smaller receptive areas than those in the LRF.

Actions of fentanyl on the fick potentials avoked by pulp stimulation

Actions of fentanyl 20 or 40 , i.v.) on the field potentials croked by pulp stimulation were suluied in 13 ats. Figure 4-B shows an example in which
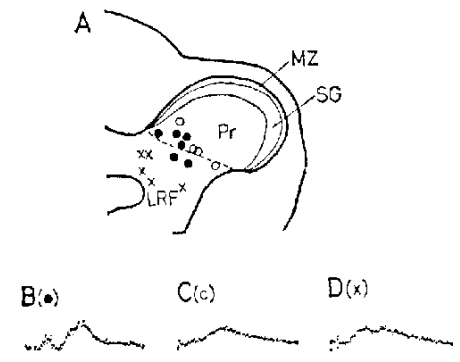

Fentany! $40 \mu \mathrm{g} / \mathrm{kg}$

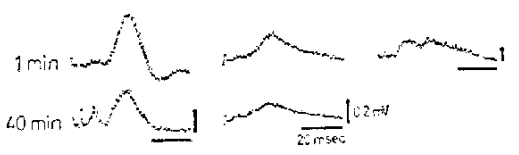

Fig. 4. Actions of fentanyl on tooth pulp evoked potentials at the subnuclcus caudalis region. Each potential is an average of 30 responses. $B$ indicates a typical example in which both the early and late phases of negative potentials were recorded and $\mathrm{C}$ indicates an example in which the late potential was prominent. These were recorded in the bordcr area between the $\mathrm{Pr}$ and the LRF. D indicates an example of the potential recorded in the ventro-medial portion in the LRF. Note that fentanyl depressed the carly phase in B, potentiated the late phase in $B$ and $C$ and did not alfect the potential in D. The locations, where responses of B ype (chised circles), ( type topen cirelesl and D lype (arosses) were recorded, are illustruted in $\mathrm{A}$, a cross section of the corvical cord $5 \mathrm{~mm}$ caudal to the obex. 
both the first and second peaks were simultaneously induced by pulp stimulation. Within 5 min after the fentanyl injection $(40 \mathrm{gg} / \mathrm{kg}$ ), the first peak of the potentials was almost abolished, while the second peak was remarkably increased in size. Thereafter, the first peak gradually recovered and returned to the control value in about $30 \mathrm{~min}$. The second peak, however, did not completely recover to the control value until, at least, $40 \mathrm{~min}$ later. A complete recovery of the later peak is exemplified Fig. 4-C. The depression of the first peak by fentanyl was observed in 6 experiments. Figure 4-C indicates an example where the later peak is prominent. One min later, fentanyl potentiated this component and this effect was almost abolished within $40 \mathrm{~min}$. The late potentiation was observed in 10 cases including those in Fig. 4-B and -C. As shown in Fig. 4-A, both depression of the early peak (closed circles) and potentiation of the late peak (closed and open circles) were observed at the border area between the $\mathrm{Pr}$ and the LRF.

The potential recorded at the ventro-medial portion of the LRF (crosses in Fig. 4-A) was hardly affected by fentanyl as shown in Fig. 4-D ( 5 experiments).

\section{Influence of fentanyl on the responses of pulp-sensitive neurons}

The effect of fentanyl ( 20 or $40 \mu \mathrm{g} / \mathrm{kg}$ i.v.) on the evoked spike discharges was studied in 24 neurons in the Pr or the LRF and in 5 neurons in the marginal zone or the substantia gelatinosa.

Figure 5 illustrates three examples of fentanyl effects on single unit discharge patterns. Five min after fentanyl injection the mean latency for a cell in Fig. 5-A was prolonged from 13.9 to $23.2 \mathrm{msec}$ and the mean number of evoked spikes per response decreased from 3.2 to 1.8 . The number of spikes discharged between 20 and $40 \mathrm{msec}$ after the first pulp shock was not however decreased but rather increased by fentanyl. In other words, spike discharges with a latency close to the first peak of the field potential induced by pulp stimulation were decreased or abolished by fentanyl, while those with a latency close to the second peak were either unchanged or increased by the drug. Neurons belonging to this type are characterized

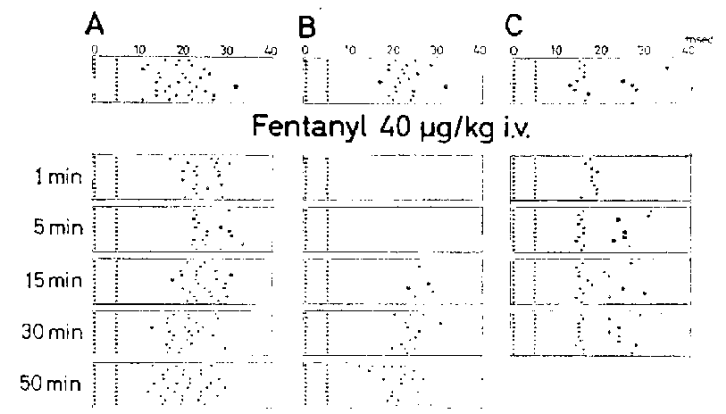

Fici. 5. Fentanyl effects on the responses of pulp-sensitive neurons to tooth pulp stimulation. These neurons (A, B and C) were located in the Pr or the LRF. Fach dot indicates a spike discharge except for the first 1 wo dots which present pulp stimulation. After fentanyl, spike latencies in $A$ were prolonged, responses in $B$ were abolished and responses in $\mathrm{C}$ were hardly changed. Note that, in $\mathrm{A}$, spike discharges between 20 and 40 msce after the first shock of pulp were rather increased after fentany]. 
by a striking prolongation of the latency after fentanyl (Fig. 6-B). A cell in Fig. 5-B discharged with a mean latency of $18.5 \mathrm{msec}$ after the first shock of paired pulp stimuli before an administration of fentanyl. This response was abolished for 5 min after fentanyl injection, and it gradually recovered and returned to the control in about $50 \mathrm{~min}$. Figure 5-C shows an example of a cell whose evoked spike discharges were hardly affected by fentanyl. Although a spike latency of this cell tended to be prolonged and its spike number to decrease 1 min after fentanyl injection, 5 and 15 min later, the responses became substantially the same as seen in the control. Since the fentanyl effect is known to last, at least, for $10 \mathrm{~min}$ $(12,18)$, the slight depression seen 1 min later may not be the effect of fentanyl per se, but rather may be due to a secondary influence such as a transient decrease in blood pressure following the injection of fentanyl.

All neurons tested were categorized into either of these 3 types, hence these were designated A (open circles in Figs. 6 and 7; early depression), B (closed circles in Figs. 6 and 7; total depression) and $C$ (crosses in Figs. 6 and 7; no depression) types according to three types shown in Fig. 5. Eight, 7 and 9 neurons were found to belong to A, B and C types, respectively. Relationship between the latency and the evoked spike number of these types of neurons is shown in Fig. 6-A. The latencies for A type neurons ranged between 10 and $15.5 \mathrm{msec}$, while those of $B$ and $C$ types scattered from 6 to $29 \mathrm{msec}$ and from 5 to $20 \mathrm{msec}$, respectively. Of $\mathrm{B}$ type, while responses of 5 neurons with latencies of more than $15 \mathrm{msec}$ were completely abolished by fentanyl, only the later discharges seen in 2 neurons responding with latencies of less than $10 \mathrm{msec}$ were depressed by the drug. Neurons which were only slightly depressed by fentanyl had mainly latencics between 5 and $10 \mathrm{msec}$. These corresponded to neurons responding with fewer spike discharges in the ventromedial portion of the LRF.

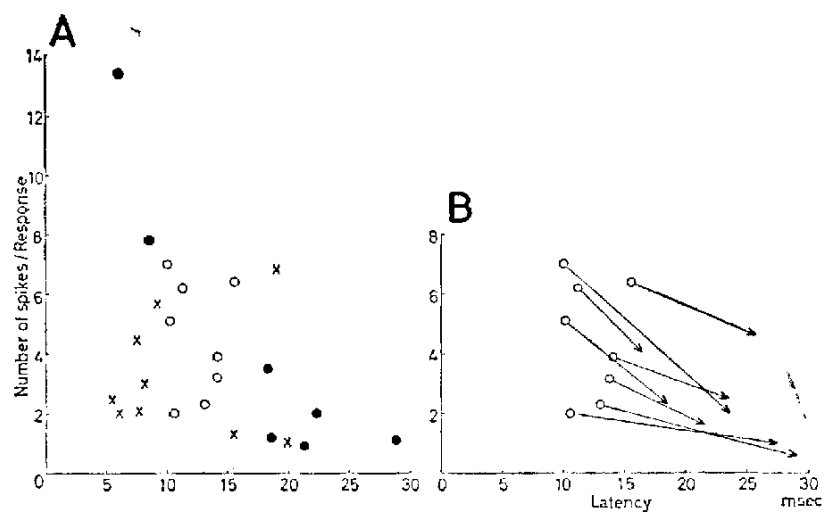

Fig. 6. Relationship between the latency of the discharge (msec, abscissa) and the cvoked spike numbers per response (ordinate) of pulp-sensilive neurons after pulp stimulation. Open circles, closed circles and crosses correspond to A, B and C-type neurons in Fig. 5, respectively. A indicates relalionship between the latency and evoked spike number of each neuron before fentanyl administration. B indicates changes of these two measures of A-type neuron after fentanyl administration. 
Locations of the above-mentioned neurons in the cord are illustrated in Fig. 7. Cells with depression (types A and B) were mainly localized in the border area between the Pr and the LRF. Neurons in the more ventro-medial portion of the LRF were hardly affected by fentanyl (type C). In 3 of the 5 cells in the marginal zone or the substantia gelatinosa, the pulp-induced spike discharges were depressed by fentanyl (latencies were 13.3, 19.9 and $82.3 \mathrm{msec}$, respectively). The responses of the other
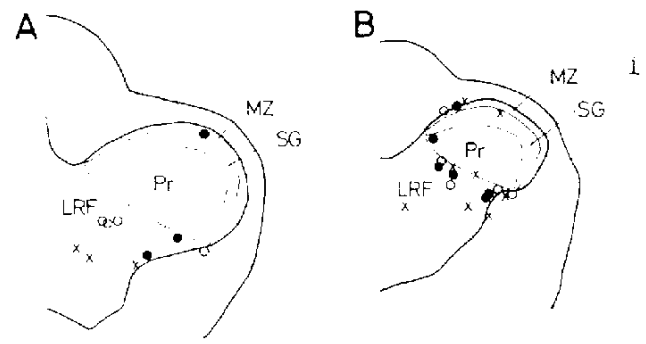

Fic. 7. Locations of pulp-sensitive neurons and effects of fentanyl. A and $B$ are cross sections of the cervical cord 3 and $5 \mathrm{~mm}$ caudal to the obex, respectivcly. Open circles, closed circles and crosses correspond to $A, B$ and $C$-type neurons in Fig. 5, respectively. two cells were not affected by the drug (latencies were 10.0 and $33.8 \mathrm{msec}$, respectively).

No definite relationship between fentanyl effect and the modality of effective stimuli or the size of peripheral receptive area was observed.

\section{DISCUSSION}

Projection of tooth pulp in the spinal trigeminal nucleus caudalis region

Our results indicate that pulp stimulation induced negative field potential in the border area between the Pr and the LRF, and that the potential is separable in two components on the basis of drug effects or stimulus-following capability. Vyklicky and his colleagues (19, 20), however, showed contradictory results. They reported in the barbiturate anesthetized cat and monkey that the field potential from pulp could not be recorded in the subnucleus caudalis. This inconsistency may be due to the use of barbiturate anesthesia, as in the unanesthetized dog the field potential with a latency of 3-4 msec was induced by pulp stimulation in the subnucleus caudalis (15) and a barbiturate in a higher dose depressed the field potential in the subnucleus caudalis region in our preliminary observation. Furthermore, a negative ficld potential recorded by Greenwood (21) in the subnucleus caudalis of the nembutal ancsthetized cat had a very small amplitude. The possibility of the current spreading to extrapulpal receptors, as pointed out by Hassel et al. (22) and Vyklický et al. (23), is unlikely in our preparations as the destruction of tooth pulp completely abolished these field potentials. The onset latency value (4.5-6.5 msec) indicates the conduction velocity $10-15 \mathrm{~m} / \mathrm{sec}$. This value is not unreasonable for the pulpal fiber with diameters of 1-7 :

Pulp-sensitive neurons were predominantly encountered in the LRF and in the border area where the field potentials induced by the pulp were recorded. They were activated by several modes of natural stimulation, including a noxious one, in wider areas of face. These response charateristies concesponded to thuse of 'B cells' of Gordon et al. (6) or 'L.RF neuron' of Nord and Kyler (7).

Eight pulp-sensitive neurons localized in the marginal zone or the substantia gelatinosa 
of the subnucleus caudalis may require speciat mention beaduse the pulp-croked potentials were not recorded in this zone. Such neurons appeated to include 'noxious units' observed by Mosso and Kruger (10) in the marginal zone, because 3 out of 4 neurons tested were not excited by touch or pressure but only by a pin prick on the face. The latencies (10-82 msec, mean $=28.9 \mathrm{msec})$ were comparable with those of 'noxious units' (6-150 msec, mean $=21.7$ nsec).

\section{Action of fentanyl}

Fentanyl depressed the first (early) peak of the field potentials evoked by pulp stimulation in the border area between the Pr and the LRF. This fentanyl effect is in agreement with the results of Mizoguchi (15) who reported that morphine (2-6 $\mathrm{mg} / \mathrm{kg} \mathrm{i.v}$.) depressed a negative field potential with a latency of $3-4$ msec at the subnucleus caudalis evoked by tooth pulp stinulation in the dog. Fentanyl remarkably potentiated the second (late) peak of pulp-induced ficld potentials. This effect seems to be related with potentiation by fentanyl of overreaction to lactile stimulation after $\alpha$-chloralose injection (our preliminary observation) rather than an analgesic action.

A question then arises as to whether or not the early (depressed by fentanyl) and late (potentiated by fentanyl) potentials originate from activities of the same neurons. Cells in the border area which had a latency of about 5-15 msec corresponding to the early potential and whose responses to pulp stimulation were depressed by fentanyl were thus studied. Ten cells which filled such criteria were found. In 8 of these, although their latencics and cvoked spike numbers after pulp stimulation were prolonged and dccreased, following fentanyl injection, their spike discharges between 20 and $40 \mathrm{msec}$ after the stimulus were not affected but rather were increased by fentanyl. Since the latency of the latter corresponds to that of the late potential, it is considered that these neurons may be responsible, at least in part, for the opposite actions of fentanyl on the early and late potentials. However, fentanyl potentiation can hardly be explained from the facts related the single neuron activities, as none of the 8 ncurons with latencies of more than $15 \mathrm{msec}$ was excited by fentanyl and even 5 depressed neurons were observed.

It was thus confirmed in this study that field potentials and unit activities evoked by tooth pulp stimulation were predominantly recorded in the border area, corresponding to the dorso-lateral part of the LRF region of Nord and Ross (9), and these potentials were depressed by fentanyl. Neurons in the LRF region, ventro-medially contiguous with the $\mathrm{Pr}$, receive a convergence of various forms of noxious and non-noxious input $(6,7,9)$, as well as those in Rexed laminae $V$ in the spinal cord dorsal horn (cf. 24, 25), and they were considered to play a fundamental role in facial pain perception by Nord and his colleagues $(7,9)$. This region is anatomically regarded as a rostral cxtension of the spinal laminae $V$ (26). Besson et al. (27) had reported that phenoperidine, a narcotic, $(0.2 \mathrm{mg} / \mathrm{kg}$ i.v. $)$ depressed spontaneous activity and nociceptive responses of laminae $V$ cells induced by natural or clectrical stimulation. Kitahata et al. (28) also obtained similar results using morphine. The effects seen with drugs parallel the observations in the present work. Thus, the fentanyl effect on neurons in this region might explain, at lcast in part, the analgesic action of a 
narcotic in the trigeminal system.

Within or near the marginal zone where Mosso and Kruger (10) recorded 'noxious unit' activities, 8 neurons activaled by pulp stimulation were encountered. The effect of fentanyl on cells in the marginal zone varied from unit to unit. Field potentials and cell activities evoked by pulp stimulation in the ventro-medial portion of the LRF werc hardly affected by fentanyl, indicating the preferential effect of fentanyl on neurons in the dorso-lateral portion of the LRF.

The present study indicates that input from tooth pulp afferents in the subnucleus caudalis region invade the marginal zone, the border area between the Pr and the LRF, and the LRF, and suggests that fentanyl depresses input to the border area from the pulp or the activities of neurons in this area.

Acknowledgements: Thanks are due to Mr. M. Mikuni for technical assistance and Miss Y. Ishii for the histological preparations.

\section{REFERENCES}

1) S.öQvist, O.: Acta psychiat, neurol. scand. Suppl. 17, I (1938)

2) Kruger, L.: Oral-Facial Sensory and Motor Mechanisms, Edited by DUbner, R. AND KAwAMura, Y., p. 135, Appleton-Century-Crofts, New York (1971)

3) Olszewski, J.: J. comp. Neurol. 92, 401 (1950)

4) Brodal, A., St.abo, T. And Torvik, A.: J. comp. Neurol. 106, 527 (1956)

5) ToRvik, A.: J. comp. Neurol. 106, 51 (1956)

6) Gordon, G., Landgren, S, And Seld, W.A.: J. Physiol. 158, 544 (1961)

7) Nord, S.G. ANd KYlfr, H.J. : J. comp. Neurol. 134, 485 (1968)

8) ScrBetTA, C.J. AND King, R.B.: J. Netrophysiol. 32, 229 (1969)

9) NoRd, S.G. AND Ross, G.S.: Brain Res. 58, 385 (1973)

10) Mosso, J.A. AND Krugfr, L.: J. Neurophysiol. 36, 472 (1973)

11) Riblet, L.A. And Mitchell, C.L.: J. Pharmacol. exp. Ther. 180, 610 (1972)

12) NishiJima, Y. ANd SakaI, Y.: Japan. J. Pharmacol. 25, 335 (1975)

13) Mitcheli, C.L.: J. Pharmacol. exp. Ther. 146, 1 (1964)

14) Brookhart, J.M., Livingston, W.K. and Haugex, F.P.: J. Neurophysiol. 16, 634 (1953)

15) Mizoguchi, K.: Folia pharmacol. japon. 60, 326 (1964) (in Japanese)

16) Kuromi, H., Sato, M. ANd TakaGi, H.: Folia pharmacol.japon. 67, $198 \mathrm{P}$ (1971) (in Japanese)

17) Gardocki, J.F. ANd Yelvosky, J.: Toxic. appl. Pharmacol. 6, 48 (1964)

18) IWATA, N. ANd SAKaI, Y.: Japan. J. Pharmacol. 21, 427 (1971)

19) Davies, W.I.R., Scott, Jr., D., Vestersirgm, K. and Vyklický, L.: J. Physiol. 218, 515 (1971)

20) Tamarova, Z.A., Shapoval.ov, A.I. AND VykilckÝ, L.: Brain Res. 64, 442 (1973)

21) GreEnwoon, F.: Archs oral Biol. 18, 771 (1973)

22) Hassel, H.J. Van, Biedenbach, M.A. and Brown, A.C.: Archs. oral Biol. 17, 1059 (1972)

23) Vyklický, l., Kellek, O., Brožek, G. and Butkhuzz, S.M.: Brain Res. 41, 211 (1972)

24) WaI.t, P.D.: I. Physiol. 188, 403 (1967)

25) Wagman, I.H. and Price, D.D.: J. Neurophysiol. 32, 803 (1969)

26) ReXrD, B.: J. comp. Neurol. 96, 415 (1952)

27) Brsson, J.M., Wyon-Maillard, M.C., Benoist, J.M., Consliller, C. and Hanann, K.F.: 1. Pharmacol. exp. Ther. 187, 239 (1973)

28) Kitahata, L.M., Kosaka, Y., Taub, A., Bonikos, K. and Hoffert, M.: Anesthesiology 41, 39 (1974) 